\title{
Serrated Colorectal Neoplasia: From Sideshow to Center Stage
}

\author{
Charles J. Kahi ${ }^{1,2}$, and Douglas K. Rex ${ }^{1}$
}

1 Indiana University School of Medicine, Department of Medicine, Division of Gastroenterology and Hepatology, Indianapolis, Indiana

2 Richard L. Roudebush VA Medical Center, Indianapolis, Indiana

Corresponding author:

Charles J. Kahi, MD, MS, FACP, FACG, FASGE, AGAF

Professor of Clinical Medicine

Indiana University School of Medicine

Gastroenterology Section Chief, Roudebush VA Medical Center

$1481 \mathrm{~W} 10$ th street, $111 \mathrm{G}$

Indianapolis, IN 46202

Phone: (317) 988-3682

Fax: (317) 988-5313

E-mail: ckahi2@iu.edu

Conflict of interest: none.

This is the author's manuscript of the article published in final edited form as:

Kahi, C. J., \& Rex, D. K. (2017). Serrated Colorectal Neoplasia: From Sideshow to Center Stage. Clinical 
In 2011, Clinical Gastroenterology and Hepatology published our study "Prevalence and Variable Detection of Proximal Colon Serrated Polyps during Screening Colonoscopy"1. It is appropriate to first put this paper in context. At the time, there had been escalating concerns about colonoscopy's imperfect protection against colorectal cancer $(\mathrm{CRC})$, with observational studies suggesting that colonoscopy was significantly less effective in preventing deaths from right-sided colon cancer than left-sided $\mathrm{CRC}^{2,3}$. In parallel, the serrated neoplasia field was undergoing profound transformation, and emerging as an important factor in the $\mathrm{CRC}$ arena. Aiming to reorganize disparate and evolving histopathological criteria, the World Health Organization had just updated its classification of serrated colorectal neoplasms, grouping lesions under 3 major categories (hyperplastic, sessile serrated adenoma/polyp, and traditional serrated adenoma $)^{4}$. In addition, progress was being made in elucidating the mechanisms involved in the serrated pathway to colorectal carcinogenesis ${ }^{5}$, including the observation that there was an overlap in the molecular features of post-colonoscopy CRCs and serrated neoplasms $s^{6,7}$. Serrated polyps are often located in the proximal colon and exhibit morphologic features which can render detection and complete resection challenging, even for experienced endoscopists. The effectiveness of colonoscopy as a screening modality depends on the quality of its performance, and variability in endoscopists' adenoma detection rates (ADR) had been associated with the risk of post-colonoscopy $\mathrm{CRC}^{8}$. However, whether and to what extent this detection variability applied to proximal serrated polyps was uncertain.

Using the Indiana University endoscopy database, we identified 6681 screening colonoscopies performed by 15 attending gastroenterologists, and determined detection rates of adenomas and serrated polyps. The proportion of colonoscopies with at least one adenoma was $38 \%$ (range $17 \%-47 \%$ ), and $13 \%$ for proximal serrated polyps (range $1 \%-18 \%$ ). Adenoma and proximal serrated polyp detection rates per colonoscopy were strongly correlated $(R=0.76, P=$ 
.0005). Endoscopist was associated with proximal serrated polyp detection ( $P<.0001)$, but patient age $(P=.76)$ and gender $(P=.95)$ were not.

Ours was one of the first studies to demonstrate that detection of serrated lesions was even more variable than detection of conventional adenomas. One previous work reported variation in serrated polyp detection rates within the same group of endoscopists ${ }^{9}$. However, the 18-fold variability in proximal serrated polyp detection we observed in the study published in CGH was novel and striking, and indicated significant shortcomings in some endoscopists' ability to recognize these lesions. This was further supported by the observation that the endoscopist performing the procedure was a powerful predictor of proximal serrated polyp detection. Studies published subsequent to our work have confirmed that detection of proximal serrated polyps can be highly variable and endoscopist-dependent ${ }^{10,11}$.

The serrated neoplasia field has evolved considerably and in exciting new directions since 2011. One development is the realization that the prevalence of the most relevant subtype of serrated polyps, the sessile serrated polyp (SSP), was higher than originally thought. We conducted a study ${ }^{12}$ including 1910 average-risk patients ( $\geq 50$ years old) who had undergone screening colonoscopy by one endoscopist with high adenoma and serrated lesion detection rates, combined with a review of all slides of serrated lesions proximal to the sigmoid colon and rectal-sigmoid serrated lesions $>5 \mathrm{~mm}$ by one expert GI pathologist. The overall SSP prevalence in this study was $8.1 \%$, of which about $7.4 \%$ exhibited cytological dysplasia. A subsequent large Dutch study ${ }^{13}$ yielded similar results. Another important development is the recognition that serrated polyps are associated with increased risk of synchronous ${ }^{14}$ and metachronous ${ }^{15,16}$ neoplasia, with one study ${ }^{15}$ showing that the risk of subsequent CRC development in patients with SSP was comparable to that of patients with conventional adenomas. Considerable progress has also been made in elucidating the molecular and clinical bases of the serrated pathway to $\mathrm{CRC}$, including the most extreme manifestation of the serrated 
milieu, the serrated polyposis syndrome ${ }^{17}$. The role of image-enhanced endoscopy to allow differentiation of SSPs from non-neoplastic lesions has been the focus of recent research, with the development of reliable algorithms such as the WASP ${ }^{18}$ optical diagnosis classification, which combines the NBI International Colorectal Endoscopic (NICE) algorithms with surface features associated with SSP (clouded surface, indistinctive border, irregular shape, and dark spots inside crypts). The optimal polypectomy techniques for serrated polyps are also being refined. The CARE study ${ }^{19}$ found that large serrated polyps were at highest risk for incomplete resection using conventional methods, likely due to their indistinct borders. However, subsequent reports ${ }^{20,21}$ showed that standardized dye-assisted endoscopic mucosal resection techniques could result in complete resection of SSPs which was at least as effective as for comparable-sized conventional adenomas.

Serrated polyps have "come a long way" from the status of relative histopathological oddity, to recognition as being CRC precursors, and a suitable target for screening on par with conventional adenomas. We believe our study was an important contribution along the way; it drew attention to the problem of variability in detection rates among endoscopists, and the need to increase efforts to educate providers to optimize recognition of serrated polyps. We are grateful to $\mathrm{CGH}$ and its Board of Editors for giving us the opportunity to share our findings with the medical community and increase awareness about the significance of serrated neoplasms. 


\section{References}

1. Kahi CJ, Hewett DG, Norton DL, Eckert GJ, Rex DK. Prevalence and variable detection of proximal colon serrated polyps during screening colonoscopy. Clin Gastroenterol Hepatol 2011;9:42-6.

2. Baxter NN, Goldwasser MA, Paszat LF, Saskin R, Urbach DR, Rabeneck L. Association of colonoscopy and death from colorectal cancer. Ann Intern Med 2009;150:1-8.

3. Singh H, Nugent Z, Demers AA, Kliewer EV, Mahmud SM, Bernstein CN. The reduction in colorectal cancer mortality after colonoscopy varies by site of the cancer. Gastroenterology 2010;139:1128-37.

4. Snover DC AD, Burt RW, Odze RD. Serrated polyps of the colon and rectum and serrated ("hyperplastic") polyposis. In: Bozman FT CF, Hruban RH, Theise N, editors., ed. WHO classification of tumours of the digestive system. Berlin: Springer-Verlag; 2010.

5. Leggett B, Whitehall V. Role of the serrated pathway in colorectal cancer pathogenesis. Gastroenterology;138:2088-100.

6. Sawhney MS, Farrar WD, Gudiseva S, et al. Microsatellite instability in interval colon cancers. Gastroenterology 2006;131:1700-5.

7. Arain MA, Sawhney M, Sheikh S, et al. CIMP status of interval colon cancers: another piece to the puzzle. Am J Gastroenterol 2010;105:1189-95.

8. Kaminski MF, Regula J, Kraszewska E, et al. Quality indicators for colonoscopy and the risk of interval cancer. N Engl J Med;362:1795-803.

9. Hetzel JT, Huang CS, Coukos JA, et al. Variation in the detection of serrated polyps in an average risk colorectal cancer screening cohort. Am J Gastroenterol 2010;105:2656-64.

10. de Wijkerslooth TR, Stoop EM, Bossuyt PM, et al. Differences in proximal serrated polyp detection among endoscopists are associated with variability in withdrawal time. Gastrointest Endosc 2013;77:617-23.

11. Payne SR, Church TR, Wandell M, et al. Endoscopic detection of proximal serrated lesions and pathologic identification of sessile serrated adenomas/polyps vary on the basis of center. Clin Gastroenterol Hepatol 2014;12:1119-26.

12. Abdeljawad K, Vemulapalli KC, Kahi CJ, Cummings OW, Snover DC, Rex DK. Sessile serrated polyp prevalence determined by a colonoscopist with a high lesion detection rate and an experienced pathologist. Gastrointest Endosc 2015;81:517-24.

13. JE IJ, de Wit K, van der Vlugt M, Bastiaansen BA, Fockens P, Dekker E. Prevalence, distribution and risk of sessile serrated adenomas/polyps at a center with a high adenoma detection rate and experienced pathologists. Endoscopy 2016;48:740-6.

14. Gao Q, Tsoi KK, Hirai HW, et al. Serrated polyps and the risk of synchronous colorectal advanced neoplasia: a systematic review and meta-analysis. Am J Gastroenterol 2015;110:501-9; quiz 10.

15. Erichsen R, Baron JA, Hamilton-Dutoit SJ, et al. Increased Risk of Colorectal Cancer Development Among Patients With Serrated Polyps. Gastroenterology 2016;150:895-902 e5.

16. Holme $\mathrm{O}$, Bretthauer $\mathrm{M}$, Eide $\mathrm{TJ}$, et al. Long-term risk of colorectal cancer in individuals with serrated polyps. Gut 2015;64:929-36.

17. Rex DK, Ahnen DJ, Baron JA, et al. Serrated lesions of the colorectum: review and recommendations from an expert panel. Am J Gastroenterol 2012;107:1315-29; quiz 4, 30.

18. IJspeert JE, Bastiaansen BA, van Leerdam ME, et al. Development and validation of the WASP classification system for optical diagnosis of adenomas, hyperplastic polyps and sessile serrated adenomas/polyps. Gut 2016;65:963-70.

19. Pohl H, Srivastava A, Bensen SP, et al. Incomplete polyp resection during colonoscopy-results of the complete adenoma resection (CARE) study. Gastroenterology 2013;144:74-80 e1. 
20. Pellise M, Burgess NG, Tutticci N, et al. Endoscopic mucosal resection for large serrated lesions in comparison with adenomas: a prospective multicentre study of 2000 lesions. Gut 2017;66:644-53.

21. Rex KD, Vemulapalli KC, Rex DK. Recurrence rates after EMR of large sessile serrated polyps. Gastrointest Endosc 2015;82:538-41. 